\title{
PEDAGOGIA CRÍTICO-PERFORMATIVA: TENSIONAMENTOS ENTRE O PRÓPRIO E O COMUM NO ESPAÇO-TEMPO ESCOLAR
}

\author{
Marcelo de Andrade Pereira ${ }^{1}$
}

RESUMO: O presente texto consiste em uma breve reflexão sobre processos de interação entre educadores e educandos no contexto de uma prática pedagógica crítico-performativa. A investigação pretende analisar os elementos que constituem um dos anelos fundantes da prática educacional: o estabelecimento de uma vida em comum em um mundo pautado pelo próprio. Dito de outro modo, o estudo procura refletir, desde os pressupostos da Pedagogia crítico-performativa, da Estética Relacional e de alguns pensadores contemporâneos - como Jacques Rancière, Tzvetan Todorov e Giorgio Agamben - , sobre o jogo entre o próprio (do singular) e o comum (do semelhante e/ou do plural) em processos formativos mediados por prática pedagógica performativa. O trabalho se apresenta, assim, como sendo de caráter ensaístico, efetuando-se por meio da exploraçáo de materiais eminentemente bibliográficos.

Palavras-chave: Pedagogia crítico-performativa. Performance. Giorgio Agamben. Estética Relacional.

${ }^{1}$ Universidade Federal de Santa Maria, Centro de Educação - Santa Maria (RS), Brasil. E-mail: marcelo.pereira@ufsm.br

DOI: $10.1590 /$ CC0101-32622017168666 


\title{
Critical-Performative Pedagogy: tensionings between the own and the common in the school space-time
}

\begin{abstract}
This text is a brief reflection on processes of interaction between teachers and students in the context of a critical-performative pedagogical practice. The research aims to analyze the elements that constitute one of the founding yearnings of the educational practice: the establishment of a common life in a world ruled by the own. In other words, the study seeks to reflect on from the assumptions of critical-performative pedagogy, Relational Aesthetics and some contemporary thinkers - such as Jacques Rancière, Tzvetan Todorov and Giorgio Agamben the game between the own (singular) and the common (the similar and/or plural) in the formative processes mediated by performative pedagogical practice. The study is presented, thus, as of essayistic character, being developed through the exploitation of eminently bibliographic materials.
\end{abstract}

Keywords: Critical-performative pedagogy. Performance. Giorgio Agamben. Relational Aesthetics.

\section{INTRODUÇÃO}

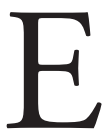

sta investigação propóe-se a problematizar os processos de interaçáo entre educadores e educandos no contexto da Pedagogia crítico-performativa. Isso implica, obviamente, examinar as condiçóes históricas, sociais e culturais que atuam sobre o sujeito na contemporaneidade, ou seja, a trama de relaçóes — dos mais diversos registros — que constituem e inscrevem o sujeito no tecido social.

A presente proposta analítica poderia soar anódina e, por que não dizer, anacrônica, porquanto se refira a uma teoria/prática pedagógica baseada em pressupostos críticos, os quais embutem noçóes deveras questionadas no âmbito da educação, como autonomia e emancipação. Tal paradigma, contudo, supóe-se por não encerrado - tal como nos antecipa Jürgen Habermas (2002), em seu texto $O$ discurso filosófico da Modernidade - um projeto emancipatório que a educação, sobretudo a formal, deliberadamente ou não, cristalizaria ou mesmo conduziria. A esse respei- 
to, talvez seja interessante recobrar os argumentos de Nicolas Bourriaud, pensador contemporâneo, o qual reitera a elaboração habermasiana acerca da Modernidade. De acordo com Bourriaud, a Modernidade não pode ser reduzida "a uma teleologia racionalista [e, sequer] a um messianismo político". E continua: "Não foi a modernidade que morreu e sim sua versão idealista e teleológica” (BOURRIAUD, 2009, p. 17).

É importante salientar, contudo, que isso não quer dizer que as construçôes teóricas posteriores às críticas não sejam pertinentes e mesmo desconsideradas, muito pelo contrário. Tais elaboraçóes, denominadas pós-críticas e/ou pós-modernas, adensarão uma investigação que se apresenta como sendo de caráter crítico - muito embora possa ela apresentar traços pós-críticos e desembocar numa prática pedagógica peculiar, compreendida por alguns autores como pós-moderna ${ }^{1}$.

Seja como for, a contemporaneidade apresenta-se para nós ainda como emblemática, engendrando, de forma veloz e, por vezes, imperceptível, formas de ser, de habitar e de se relacionar no mundo, em nosso caso, no contexto da formaçáo, requerendo, assim, abordagens de análise - sejam elas quais forem - que permitam a criação ou mesmo a reconfiguraçáo de conceitos que possam se aproximar do tempo presente, a fim de indicar possibilidades de intervenção caso elas se façam necessárias ou mesmo possíveis.

Cabe, então, indagar: como ou pelo que se caracterizam, no tempo presente - naquilo que comumente chamamos de contemporâneo - e no contexto da formação, as relaçóes humanas? A resposta a essa pergunta não é difícil de ser enunciada: individualidade, coisificação dos sujeitos, coisificação das relações sociais, descartabilidade, imediatez, superficialidade, impermanência, interatividade, virtualização do real e da presença, mecanização dos gestos e automatismo da linguagem, ubiquidade. Parte-se, aqui, do dado e não do idealizado. Dito de outro modo, a investigação não procura prejulgar de funçóes o contemporâneo, mas compreendê-lo, acolhê-lo nas suas formas de aparição, para que a presente empreitada seja, de fato, pertinente e atual.

Em um mundo dominado pelas tecnologias de informação e comunicação, as quais encerram "os contatos humanos dentro de espaços de controle que decompóem o vínculo [social] em elementos distintos", tornando-o "um produto padronizado", a única possibilidade de escape 
que se nos dá a ver reside, ainda, no estabelecimento de "formas extremas ou clandestinas" de se inscrever e se relacionar no espaço social (BOURRIAUD, 2009, p. 11-12) ${ }^{2}$.

Esse texto parte, portanto, da premissa de que uma prática pedagógica crítico-performativa seria capaz de criar um espaço multirreferencial de sentidos, em que se possa rediscutir o individual e o plural, o semelhante e o diferente no contexto da formação, e, por conseguinte, das relaçóes sociais e dos dispositivos e elementos de subjetivação que constituem e/ou inscrevem os sujeitos no espaço do comum.

Parece-nos, pois, autoevidente que as tecnologias de informação e comunicação não apenas alteraram o curso das relações humanas — antes pautadas por outras formas de socialização, tomadas por rudimentares na visão de muitos neófitos da geração High-Tech — como também atuaram em um registro muito mais profundo, que se refere à mutação dos processos de cognição e subjetivação humana, tal como se pode verificar na ascensão da geração supramencionada. Em outras palavras, o sujeito não apenas se relaciona com o outro de uma forma qualitativamente distinta daquela que até recentemente considerávamos "normal", "legítima”, "natural" como também acessa o mundo e se inscreve nele por meio desses dispositivos informacionais e comunicacionais.

Assim, faz-se necessário ponderar que sequer as faculdades cognitivas, como a percepção e a atenção, podem hoje ser compreendidas à luz de uma teorização psicológica e pedagógica que não leve em consideração o impacto das tecnologias supracitadas. É interessante pontuar, ainda, que a diagnose presente nessas afirmaçóes não é propriamente nova, porquanto tenha sido como que prenunciada, já em meados do século passado, pelo filósofo alemão Walter Benjamin (1989). Para aquele momento, contudo, o foco de Benjamin se dirigia a uma nova forma de recepção — surgida com o advento das sociedades industriais —, que dificultaria ou mesmo impediria o acesso dos indivíduos a determinadas formas de expressão artísticas e literárias, obliterando, por conseguinte, a ocorrência de uma qualidade determinada de experiência ${ }^{3}$.

Registre-se, assim, que o presente texto não se arrisca a adentrar no âmbito da pesquisa das novas tecnologias educacionais - ainda que a elas se relacione e se refira. Este estudo procura, tão somente, tematizar em sua introdução o impacto das tecnologias de informação e 
comunicação, em vista de situar o sujeito contemporâneo da educação na contemporaneidade - e as relaçóes por ele constituídas com os outros e, também, com e por intermédio desses e de outros meios ${ }^{4}$.

Há, por certo, uma infinidade de pesquisas (necessárias) que se debruçam de maneira exaustiva, rigorosa e consequente sobre as relaçóes dos sujeitos ensinantes e aprendentes com e/ou no interior dessas novas tecnologias. O intuito deste artigo é, todavia, mais humilde, restringindo a análise ao campo das relaçóes interpessoais em contextos formativos orientados/mediados pela Pedagogia crítico-performativa — que é balizada pela presença corpórea dos sujeitos e não apenas virtual.

Com efeito, não se pode pensar a performance e, por conseguinte, a Pedagogia crítico-performativa sem a presença do corpo e sua dimensão expressiva. O expressivo, aqui, refere-se a algo mais abrangente que o artístico, dizendo respeito à possibilidade de tornar visivel, por meio de uma teoria/prática pedagógica peculiar, formas de aparição do sujeito que não são necessariamente acolhidas — e, por vezes, teoricamente não passíveis de serem acolhidas — no âmbito do comum. É preciso, assim, perguntar, no curso desta investigação, sobre o que constitui um comum e o próprio que dele participa.

$\mathrm{Na}$ prospecção teórica a ser realizada adiante, veremos como Jacques Rancière (2005), Giorgio Agamben (2013) e Tzvetan Todorov (2014) podem fornecer subsídios para se pensar a equação próprio-comum desde o campo educacional, em vista, obviamente, das teorizaçóes advindas da Pedagogia crítico-performativa, da Pedagogia da arte da performance e dos estudos da performance na educaçáo, desenvolvidas por autores como Elyse Lamm Pineau, Peter McLaren, Charles Garoian, entre outros.

Em um mundo que prescinde do outro, do corpo, da presença, faz-se mister reconfigurar, por meio de uma reflexão rigorosa, as formas contratuais que se estabelecem no âmbito formativo e que se irradiam no interior do próprio tecido social, amalgamando-o, dando-lhe liga. O estudo em tela tem, portanto, como dínamo o exame do funcionamento das relaçóes humanas — das interaçóes, do contato —, no par própriol comum, desde o âmbito social e educacional, e sua eventual remodelação a partir de uma teoria/prática pedagógica crítico-performativa. Reitera-se, por fim, o anelo principal desta investigação, ou seja, a tentativa de constituição de um corpus teórico que permita fazer repicar alguns pro- 
blemas caros à pesquisa educacional brasileira e contemporânea - aqui, o problema da alteridade, do contato, das relaçóes sociais — em face da Pedagogia crítico-performativa.

\section{DA PEDAGOGIA CRÍTICO-PERFORMATIVA}

Para levarmos a termo a proposta de análise acerca dos modos como são pensados, no contexto contemporâneo e da Pedagogia crítico-performativa, o próprio e o comum - no que tange às relaçôes estabelecidas entre sujeitos envolvidos em processos formativos - , apresentar-se-á, de forma concomitante, um conjunto de elaboraçôes teóricas e conceituais a partir das quais a pesquisa se formula.

De acordo com Elyse Lamm Pineau, uma das pioneiras dessa "nova e radical (poética) da pesquisa educacional", a Pedagogia crítico-performativa nasce, fundamentalmente, da tentativa de articulaçâo de "interseçôes gerativas entre (a) performance e (a) pedagogia" (PINEAU, 2010, p. 90).

O empreendimento teórico/prático de Pineau está, por certo e diferentemente do que havia sido realizado por outros pesquisadores antes dela -, associado tanto aos Estudos da Performance quanto à Pedagogia da Libertação, corrente teórico/prática propalada, desde o final do século XX, pelo pensador brasileiro Paulo Freire (PINEAU, 2005; 2010; 2013). Ao se balizar pelos pressupostos da Educaçáo Libertadora e se munir dos achados de autores como Dwight Conquergood - no que se refere à passagem das performances artísticas às performances culturais e Peter McLaren - acerca dos ritos performativos presentes nos processos escolares -, Pineau, com outros educadores e pesquisadores críticos, procurou e ainda procura dar maior consistência à analogia criada no início dos anos de 1980 do ensino como performance (PINEAU, 2010).

Como já se observou, a Pedagogia crítico-performativa consiste em uma poética educacional, pautada, a rigor, pela presentificaçâo de conteúdos socioculturais, que se efetua por intermédio da performance e/ou de açôes performativas, por sujeitos em processos formativos. Porquanto seja gerada da interseção entre a performance e a Pedagogia, a Pedagogia crítico-performativa procura reenquadrar 
[...] todo o empreendimento educacional como um conjunto mutável e contínuo de narradores, histórias e performance, mais do que a simples e linear acumulação de competências disciplinares específicas e isoladas. (PINEAU, 2010, p. 97)

Ainda que essa definição soe genérica, pode-se dizer que ela guarda consigo, de forma implícita, as qualidades de uma peculiar forma de atuação, mais pedagógica do que propriamente artística, a qual se caracterizaria por seu caráter participativo, plástico, paradoxal, lúdico, reflexivo, multicentrado, processual, indeterminado e inacabado, multi e interdisciplinar, tal como nos faz notar Charles Garoian (1999) 5 .

Uma vez pautada pela "presentificação de conteúdos socioculturais”, a Pedagogia crítico-performativa encontra-se como que enleada a um processo de materialização de sentidos, dados e produzidos, intra e intersubjetivos, a partir do qual se constitui um próprio - e o que dele se dá a ver e/ou faz ver - e um comum, como diferença e/ou semelhança, no decurso da ação educativa; presentificar implica, então, tornar algo visível, tangível, tornar um próprio, qualquer, passível de ocupar um lugar no espaço do comum.

Sublinhe-se, em tempo, que a noção de presença não pode ser aqui reduzida a uma metáfora meramente operacional, visto ser da ordem das grandezas. Dito de outro modo, a presença denota uma espacialidade e não uma temporalidade, uma duração. Tal conceito se sedimenta nas formulaçóes sobre a sua própria produção, a experiência estética, a materialidade da comunicação e o caráter histórico e cultural da sensibilidade, no conjunto das obras de Hans Ulrich Gumbrecht (1998; 2004), que será analisado, de maneira pormenorizada, no decurso da pesquisa propriamente dita.

Outrossim, vale assinalar que o conceito de presença ${ }^{6}$ exerce, no plano da investigação proposta, uma funçáo substitutiva, visto que as significaçóes oferecidas pelos conceitos de encarnação (enfleshment) e reencarnação (refleshment) — deveras sedimentados por teóricos da Pedagogia crítico-performativa como Pineau (2005; 2010; 2013) e McLaren (1992), e empregados para explicar os processos de absorçáo por parte do sujeito de um conjunto de marcas distintivas, identitárias que operariam 
como signos de reconhecimento de um comum e de seus imperativos correlatos — não são de modo algum suficientes. Sobre esses conceitos, por exemplo, Pineau (2005) postula o seguinte:

[...] a encarnação (enfleshment) diz respeito a "um processo por meio do qual um corpo adquire certos hábitos durante um longo período. Esses hábitos se sedimentam de forma a aparentar serem naturais [...] em vez de construçóes culturais". A reencarnação (refleshment), por outro lado, remonta "à habilidade inata de um corpo de aprender comportamentos alternativos. Hábitos podem ser quebrados; o que foi aprendido pode ser desaprendido e novas maneiras de ser podem ser desenvolvidas, sendo mais capacitadoras que as maneiras antigas. (PINEAU, 2005, p. 44)

A suposição feita anteriormente acerca da insuficiência dos conceitos de encarnaçáo e reencarnaçáo no contexto da Pedagogia crítico-performativa se radica no fato de esses não aventarem a possibilidade de existência de um próprio-qualquer, compreendido como o possivel, mas, tão somente, de um próprio circunscrito por um comum, um próprio-comum.

A utilização do conceito de presença ${ }^{7}$ - à revelia dos conceitos de encarnação e reencarnação - busca, portanto e em suma, a salvaguarda da possibilidade de materialização de uma forma de vida qualquer [hipotética], visto que se refere a algo como o reconhecimento do irromper de uma singularidade absoluta, não aderente, e mesmo refratária, a um comum embora possa dele participar. Nos conceitos de encarnação e reencarnação, as gradaçóes, as tonalidades do próprio — as quais constituiriam também um qualquer - seriam como que subsumidas pelo comum. Nesses conceitos, a aparição implica sempre adesão, ao passo que, sob o conceito de presença, o que aparece não necessita ser de todo imantado, capturado, ele simplesmente orbita, lá está, aparece, dá-se a ver, não demandando e sequer sendo passível de ser enquadrado; ele lá está e ao estar lá ocupa um lugar no espaço de um comum, sem com este se plasmar.

Seja como for, pode-se afirmar que as ponderaçóes feitas acerca do conceito de presença - e não precisamente daqueles de encarnação e reencarnação, conceitos já absorvidos pela Pedagogia crítico-performativa- 
encontram-se sobremaneira ligadas, ainda que indiretamente, àquilo que Jacques Rancière denominou como a partilha do sensivel. Ou seja,

[...] o sistema de evidências sensíveis que revela, ao mesmo tempo, a existência de um comum e dos recortes que nele definem lugares e partes respectivas. Uma partilha do sensível fixa portanto, ao mesmo tempo, um comum partilhado e partes exclusivas. Essa repartição das partes e dos lugares se funda numa partilha de espaços, tempos e tipos de atividade que determina propriamente a maneira como um comum se presta à participação e como uns e outros tomam parte nessa partilha. (RANCIÈRE, 2005, p. 15)

$\mathrm{Na}$ base dessa definiçã̃o de Rancière, verifica-se o laço que une o estético ao político. O emparelhamento desses domínios apresenta-se, pois, como de fundamental importância na constituição de uma Pedagogia crítico-performativa e, também, para o exame das relaçóes entre o próprio e o comum por meio dela estabelecidas. Ao discorrer sobre formas de atuação — fazer/ser - que permitem fazer "ver quem pode (ou não) tomar parte no comum” (RANCIÈRE, 2005, p. 16), Rancière procurou tornar legível o modo como determinadas formas de vida e atividades são ou não passíveis de serem inscritas no espaço de um comum $^{8}$.

Contudo, para que se possa compreender a real amplitude dessas colocações, é preciso discutir, ainda que tardiamente, sobre os conceitos de próprio e comum - como também de suas variantes. Vejamos, então, de maneira um tanto quanto programática, como se condensam os conceitos de próprio e comum nas produçóes de Todorov e Agamben, que, na companhia de Rancière — já devidamente introduzido —, constituem os principais intercessores dessa investigação.

\section{DO PRÓPRIO E DO COMUM}

$\mathrm{Na}$ obra de Giorgio Agamben, a singularidade do ser, que designaria aqui e, em parte, um próprio, ocupa um lugar de fundamental importância. $\mathrm{Na}$ análise à Comunidade que vem, Agamben pensa o 
próprio não como um gênero ou um indivíduo mas antes como uma maneira nascente, "um ser que é $o$ seu modo de ser" e "não um ser que $e ́$ em tal ou tal modo" (AGAMBEN, 2013, p. 34). O próprio constitui-se como um "ter-lugar de uma singularidade qualquer", não sendo acidental e sequer necessário; ele designa, na verdade, aquilo que é "continuamente gerado a partir da própria maneira”. Nesse sentido, nenhuma propriedade o determina, nenhuma essência o identifica: é a "impropriedade" que o circunscreve, sua marca é a diferença e a insubstitutividade, o próprio se refere, em suma, a um livre "uso de si", um hábito, um ethos (AGAMBEN, 2013, p. 35), "um lugar vazio em que é possível para cada um mover-se livremente" (AGAMBEN, 2013, p. 32).

O comum, por outro lado, constitui-se como esse lugar a partir do qual todos os possíveis pertencimentos fazem-se passíveis de serem fundados; isso não quer dizer, contudo, que o comum possa ser reduzido a uma estrutura vinculativa ou mesmo fusional (AGAMBEN, 2013). O comum está, para Agamben, em um registro diferente daquele invocado pelo social, que se caracteriza, desde essa notação conceitual, como um espaço de plena simetria, coletivo. Sua comunidade que vem tem como fundamento o conjunto de singularidades, evidentemente assimétricas, dissonantes, as quais não precisamente se coadunam entre si, estabelecendo outro plano relacional no qual o Outro pode de fato intervir. Faz-se perceptível, portanto, um viés sutilmente utópico que trespassa o pensamento agambeniano acerca do próprio e do comum.

Vale assinalar, entretanto, que o termo singularidade náo permanecerá tal e qual durante toda a obra de Agamben, sendo posteriormente substituído, como se pode observar — a partir e - em suas Profanaçôes, pela noção de "ser especial". Ou seja,

[...] o ser cuja essência coincide com seu dar-se a ver, com sua espécie. O ser especial é absolutamente insubstancial. Ele não tem um lugar próprio, mas acontece a um sujeito, e está nele como um habitus ou modo de ser, assim como a imagem está no espelho. A espécie de cada coisa é sua visibilidade, e sua pura inteligibilidade. Especial é o ser que coincide com o fato de se tornar visível, com sua própria revelação. (AGAMBEN, 2007, p. 52) 
Diferentemente de Agamben, Tzvetan Todorov funda o seu comum no social, de modo que o equacionamento entre esses termos deságua em uma espécie de reconhecimento a que o crítico italiano se contraporia veementemente. Agamben é contrário ao pareamento das identidades ou, como ele próprio denominaria, das maneiras nascentes que constituiriam tais "singularidades". Essa diferença acerca do que venha a ser o comum nos autores supracitados não é oriunda apenas de uma distinta ordenação epistemológica — Agamben é um filósofo e Todorov um antropólogo —, mas do firme engajamento que caracteriza uma dentre as duas formas de pensar o jogo entre o comum e o próprio. De acordo com Todorov,

[...] a antropologia [...] distingue-se [...] daquilo que costumamos designar filosofia [...] por ocupar-se de um objeto empírico, o ser humano, em vez de propor-se a um exame dos princípios e dos prolegômenos, das possibilidades e das impossibilidades do conhecimento, do julgamento ou da própria existência. (TODOROV, 2014, p. 10)

Todorov, por certo, ocupa-se menos em definir os termos do próprio e do comum e mais com as relaçóes que se pautam entre estes, as quais seriam, segundo ele, observáveis e passíveis de descrição e análise (TODOROV, 2014, p. 10). Em sua Vida em comum, o pensador búlgaro discorre sobre as mais variegadas concepções de natureza humana, esforço realizado por meio do escrutínio de um conjunto bastante abrangente de teorias, as quais ressaltam ora a inclinação do homem a uma vida em comum, ora ao evitá-la em prol da realização plena de um próprio. O problema de Todorov é da ordem da intersubjetividade, ao passo que o de Agamben é existencial, ontológico e político.

Seja como for, ambos os autores fornecem, com suas penetrantes ponderaçóes, subsídios para que possa ser pensada a relação do próprio com o comum, a inscrição do diferente no mesmo, do assimétrico em relaçáo ao simétrico. O rastreamento das premissas de Agamben e de Torodov, assim como as de Rancière, em torno desses termos e dos problemas correlatos, permitirá o exame da transfiguração das relaçóes no contexto de uma Pedagogia crítico-performativa, a qual enseja, fundamentalmente, dar a ver o que se dá a ver da maneira tal como se apresenta. 


\section{DE UM POSSÍVEL, MUITOS}

Reconhecer que nossas vidas estão estruturadas de acordo com modos de comportamento repetidos e socialmente sancionados levanta a possibilidade de que qualquer atividade humana possa ser considerada como performance, ou, pelo menos, que toda atividade é executada com uma consciência de si mesma. (CARLSON, 2010, p. 15)

Um mundo obcecado pela simulação e pela teatralização nos habita. A intuição de Carlson é reveladora e, ao mesmo tempo, indicadora da potencialidade crítica da performance no campo da ação humana. Embora o termo performance seja de ampla significação, o emprego dele no contexto de uma Pedagogia permite-nos refletir sobre o modo como constituímos - e somos constituídos - um comum travestido de próprio. Nesse próprio não há, contudo, um qualquer que lhe preencha.

Porquanto se apresente como um dispositivo de disseminação de um comum, de uma cultura — e de um sistema de identificação correlato —, a escola acaba por servir, não raro, aos propósitos do poder e do saber hegemônicos, que plasmam formas de ser adequadas a sua manutenção. Entretanto, como sendo espaço de ociosidade, tal como nos lembram Masschelein e Simons (2013), a escola — a qual resiste bravamente à sua conversão em (mais) um espaço de trabalho — constitui um campo de batalha em que pode se fazer presente um processo dis-ruptivo, não consensual, de reconhecimento das coisas e dos seres que são à sua maneira, que não se deixam encapsular por categorias preestabelecidas.

Em seu célebre estudo Rituais na Escola: em direção a uma economia politica de símbolos e gestos na educação, Peter McLaren (1992) torna evidente um processo de modelaçáo dos corpos no espaço escolar - o qual se constitui, fundamentalmente, pelo hábito, pela repetição de comportamentos já consolidados — que tende a naturalizar o que é socialmente construído, destituindo daquilo que não se deixa enquadrar o que lhe é próprio. O processo de escolarização refere nesse entendimento um processo de reproduçáo performativa. McLaren, contudo, atenta para dispositivos de resistência, os quais se plasmam em um sistema de 
rituais que ora revitalizam - em que se renova o compromisso com o comum -, ora intensificam - em que se investe no estabelecimento de um comum -, ora desestruturam as relaçóes entre o próprio e o comum (MCLAREN, 1992, p. 126-128). Essa notação conceitual permite, pois, compreender a escola não apenas como um espaço de reprodução, mas como um território de integraçáo do que não pode ser integrado, de um qualquer que escapa a um comum, como terra de todos e de nenhum.

A Pedagogia crítico-performativa funciona, nesse sentido, tanto como uma "metodologia crítica", quanto uma "modalidade de exposição", de irrupção do qualquer. O bascular entre o método e a exposição da Pedagogia crítico-performativa fixa, portanto, um ponto por intermédio do qual se torna possível um salto imaginativo dentro de "outros modos de ser no mundo; ao fazê-lo, ela abre para possibilidades concretas de resistência, reforma e renovação" (PINEAU, 2013, p. 52).

Esse salto para dentro de "outros modos de ser no mundo" não implica apenas o re-conhecimento de um outro, de uma diferença, mas, sobretudo, o reconhecimento da impossibilidade de delimitação de um ser cujo limite é inexistente, é qualquer, alheio e refratário à toda e qual-quer tentativa de enquadramento. A Pedagogia crítico-performativa se mostra, então, como um processo intercorporal - visto que implica corpo, presença - como diferença e não $d a$ diferença. Se o como aventa, aqui, um comum em que transitam uma profusão de formas de vida, de modos de ser, o de refere sempre uma relação de pertencimento. O termo transitar permite, por fim, recobrar a significação de algo que não pertence senão ao que não se deixa pertencer, que pertence ao não pertencimento - o qual não constitui em si um gênero, mas, antes, um momento no qual o qualquer dá-se a ver, expóe-se.

Como sendo processo intercorporal, a Pedagogia crítico-performativa supóe o compartilhamento de sentidos, dados e produzidos, a fim de tornar possível a problematização acerca do modo "como conhecemos a nós mesmos e ao mundo ao nosso redor" - o qual é performativamente construído - e não apenas atuado, interpretado - e criado em relação com outras formas de vida (SPRINGGAY; FREEDMAN, 2007, p. XXII). É essa fluidez e a abertura que marcam a Pedagogia crítico-performativa como processo dis-ruptivo e de risco (SPRINGGAY; FREEDMAN, 2007, p. xxv). 
Em outras palavras, pode-se dizer que a Pedagogia crítico-performativa permite interrogar, resistir e intervir no espaço de um comum; como sendo prática cultural, ela "designa uma forma liberadora de ação; [...] refletindo o vivido, relacionando-se, portanto, com o múltiplo, com o diverso, com o diferente" (PEREIRA, 2013, p. 32).

Seja como for, o tracejamento teórico aqui encetado pretendeu tão somente delinear o campo a partir do qual poder-se-á elaborar uma teoria da Pedagogia crítico-performativa desde a conjuminação da filosofia, da arte, da antropologia e da educação. Daqui parte uma pequena, porém fértil tentativa de tensionamento de conceitos que são caros ao campo de que surge e para o qual se dirige, e, por conseguinte, de importância crucial para a compreensão do lugar daquele que, a rigor, não tem lugar, o próprio, no espaço do comum.

\section{REFERÊNCIAS}

AGAMBEN, G. A comunidade que vem. Belo Horizonte: Autêntica, 2013. . Profanaçôes. São Paulo: Boitempo Editorial, 2007.

. Signatura Rerum - sobre el método. Barcelona: Editorial Anagrama, 2010.

BENJAMIN, W. Sobre alguns temas em Baudelaire. In: . Charles Baudelaire: um lírico no auge do capitalismo. Obras Escolhidas III. São Paulo: Editora Brasiliense, 1989.

BOURRIAUD, N. Estética relacional. São Paulo: Martins Fontes, 2009.

CARLSON, M. Performance - uma introdução crítica. Belo Horizonte: UFMG, 2010.

GAROIAN, C. Spectacle pedagogy: art, politics, and visual culture. New York: State University of New York Press, 2008.

Performing pedagogy: toward an art of politics. New York: State University of New York Press, 1999.

GUMBRECHT, H.U. Production of Presence: what meaning cannot convey. Stanford: Stanford University Press, 2004. . A modernização dos sentidos. São Paulo: Editora 34, 1998.

HABERMAS, J. O discurso filosófico da modernidade. São Paulo: Martins Fontes, 2002. 
ICLE, G. Estudos da Presença: prolegômenos para a pesquisa das práticas performativas. Revista Brasileira de Estudos da Presença, [S.1.], v. 1, n. 1, p. 9-27, jun. 2011. Disponível em: <http://www.seer.ufrgs.br/index.php/presenca/ article/view/23682/13690>. Acesso em: 23 ago. 2016.

.Études de la présence: pour une approche non interprétative du processus de création des pratiques performatives brésiliennes, Cultures-Kairós [En ligne], v. 1, n. 1, 2012. Disponível em : http://revues.mshparisnord.org/cultureskairos/ index.php?id=507. Acessado em: 23 ago. 2016.

ICLE,G.;DALBELO,M.APerformancedaOralidadeDocente.Educação(UFSM), Santa Maria, p. 529-540, nov. 2014. Disponível em: $\leq$ http://periodicos.ufsm.br/ reveducacao/article/view/13936>. Acesso em: 23 ago. 2016. doi: 10.5902/198 4644413936

MASSCHELEIN, J.; SIMONS, M. Em defesa da escola: uma questáo pública. Belo Horizonte: Editora Autêntica, 2013.

McLAREN, P. Rituais na escola. Porto Alegre: Vozes, 1992.

PEREIRA, M.A. Sob o signo de Satã: tempo e experiência na modernidade de Benjamin e Baudelaire. Trama Interdisciplinar, São Paulo, ano 1, v. 1, p. 99-112, 2010.

- Performance docente: sentidos e implicaçóes pedagógicas. In:

(Org.). Performance e Educação: [des] territorializaçôes pedagógicas. Santa Maria: UFSM, 2013.

PINEAU, E.L. Pedagogia crítico-performativa: encarnando a política da educação libertadora. In: PEREIRA, M.A. (Org.). Performance e Educação: [des] territorializaçóes pedagógicas. Santa Maria: UFSM, 2013.

- Nos cruzamentos entre a performance e a pedagogia: uma revisáo prospectiva. Educação \& Realidade, Porto Alegre, v. 35, n. 2, 2010.

RANCIÈRE, J. A partilha do sensivel - estética e política. São Paulo: EXO Editorial, 2005.

REVISTA BRASILEIRA DE ESTUDOS DA PRESENÇA. Porto Alegre: UFRGS, (2011-), ISSN 2237-2660. Disponível em: www.scielo.br/rbep

SPRINGGAY, S.; FREEDMAN, D. Introduction: On Touching and a Bodied Curriculum. In: (Ed). Curriculum and the Cultural Body. New York: Peter Lang Publishing, 2007, p. xvii-xxvii.

TODOROV, T. A vida em comum - ensaio de antropologia geral. Sáo Paulo: UNESP, 2014. 


\section{NOTAS}

1. Ver, por exemplo, Charles Garoian (1999; 2008; 2013), para quem práticas pedagógicas mediadas pela arte da performance caracterizam-se como pós-modernas.

2. Bourriaud refere-se aqui a dispositivos artísticos, como o Happenings, a Performance. Sua investigação parte do campo da arte, mas não se restringe a este.

3. Uma análise pormenorizada deste ensaio benjaminiano que discorre sobre o processo de mutação da sensibilidade nas sociedades ocidentais pode ser encontrada no artigo Sobre o signo de satã: configuraçóes do tempo e da experiência na modernidade de Benjamin e Baudelaire, de Marcelo de Andrade Pereira (2010).

4. Ao distinguirmos o "sujeito contemporâneo da educação" da "educação (na contemporaneidade)", buscamos apenas sublinhar o caráter por vezes anacrônico que podem adotar algumas abordagens correntes no campo da pesquisa educacional e que, como mencionamos, não levam em consideraçáo as condições reais a partir das quais se estabelecem tanto relações sociais quanto relaçóes de ensino e aprendizagem.

5. Esses adjetivos guardam nítida semelhança com os princípios mais elementares da arte da performance.

6. Sobre esse conceito veja a pesquisa de Icle $(2012,2014)$ sobre Estudos da Presença e a publicaçâo brasileira dedicada ao tema: Revista Brasileira de Estudos da Presença (2011-).

7. É preciso, nesse sentido, lembrar que “[...] a presença não é senão uma experiência de presença partilhada" e que "[...] não há, assim, por que falar na natureza da presença ou na sua essência, a presença é sempre um movimento. E como experiência em movimento, ela supóe uma cultura particular que lhe confere um lugar de enunciação e um modo de percepção" (Icle, 2013, p. 16).

8. Veremos, adiante, de que maneira essas intuiçóes se coadunam com a argumentação de Giorgio Agamben acerca das formas de vida, tornando ainda mais aparente essa nem sempre harmônica relação entre o próprio e o comum.

Recebido em 04 de outubro de 2016.

Aprovado em 23 de fevereiro de 2017. 